\title{
Keynes e o conceito de capital: reflexões epistemológicas a respeito das premissas sraffianas da Teoria Geral
}

\section{ALAIN HERSCOVICI*}

Keynes and the concept of capital: some epistemological observations in regard to the Sraffian premises of the General Theory. This article aims to examine the conception of the nature of capital used by Keynes in the General Theory, to show to what extent this concept is similar to Sraffa's conception, and to highlight the implications related to this concept, in terms of structural instability. So I will study the mechanisms that explain the investment decision in an environment with strong uncertainty, the modalities of aggregation of different generations of capital and the instability of equilibrium. The convergence between the Keynesian and the Sraffian approaches comes from this common conception of capital. Finally, I will examine the implications in regard to the structure of the aggregate models.

Keywords: Long term expectations; structural instability; capital aggregation; rate of interest.

JEL Classification: B41; E11; E12.

Keynes (...) was extremely skeptical of the traditional view that one could identify something called a quantity of capital independent of values. Surely, under the influence of Sraffa (...), Keynes went so far as to rule out the logical possibility of the phrase marginal productivity of capital Rotheim Roy J., Keynes and the marginalist theory of distribution, Journal of Post Keynesian Economics, 1998, vol. 20, n. 3

\footnotetext{
* Doutor em Economia pelas Universidades de Paris I Panthéon-Sorbonne e de Amiens, Coordenador do Grupo de Estudo em Macroeconomia (GREM) do Departamento de Economia da UFES, Professor do Mestrado e pesquisador do CNPq. E-mail: alhersco.vix@terra.com.br). Submetido: 26/Outubro/2011; Aprovado: 17/Outubro/2012.
} 
Este trabalho pretende sistematizar certos resultados enunciados por Pasinetti (1997) e por Rotheim (1998), no que concerne à concepção desenvolvida por Keynes, na Teoria Geral (TG), a respeito da natureza do capital. Mostrarei por que tal démarche ressalta os fundamentos pré-sraffaianos da TG.

Contrariamente à concepção tradicional na qual o sistema keynesiano fornece uma análise de curto prazo, e os preços de produção a posição de longo prazo do sistema (Amadeo e Dutt, 1987), este trabalho propõe-se a estudar essas convergências a partir de uma concepção comum relativa à natureza do capital.

Essas convergências se relacionam com as modalidades de determinação das variáveis distributivas: Keynes recusa o segundo postulado da teoria clássica (TG, p. 25), e a Teoria dos Fundos de Empréstimos (TFE) (TG, capítulo XIV), e demonstra que a taxa de juros tem que ser determinada exogenamente. A controvérsia de Cambridge mostra que a determinação das variáveis distributivas (taxa de salários e taxa de lucro) é exógena e que uma quantidade de capital agregada não pode ser avaliada independentemente do valor dessas mesmas variáveis. É assim possível afirmar que, tanto na TG quanto nas análises neorricardianas, não há mercado do trabalho nem do capital, no sentido neoclássico. Esta concepção da natureza do capital ressalta a instabilidade estrutural do sistema capitalista (Vercelli, 1985), ou seja, o fato do sistema produzir, de maneira endógena, flutuações.

Assim, os seguintes temas serão analisados:

i) a maneira como é possível agregar capitais heterogêneos; as modalidades de agregação de várias gerações de capitais já anunciam a controvérsia relativa à mensuração do capital e à controvérsia de Cambridge ${ }^{1}$;

ii) os elementos que permitem explicar o ciclo, ou seja, a alternância entre expansão e recessão; mostrarei como o conceito de escassez (ou de abundância) de capital e as modificações das expectativas, no decorrer do ciclo, permitem explicar este movimento.

Uma primeira parte tratará das modalidades de construção da função agregada de investimento; uma segunda parte estabelecerá um paralelo entre Keynes e a economia clássica e, mais especificamente, entre Keynes e a economia neorricardiana, e mostrará como, a partir desta concepção comum, é possível fornecer uma explicação endógena do ciclo econômico.

\section{OS DETERMINANTES DO INVESTIMENTO}

\section{Os instrumentos de análise}

\section{Preço de oferta, preço de demanda e eficiência marginal do capital}

Inicialmente, o significado dos conceitos de preço de oferta e de demanda se relaciona diretamente com a análise de Marshall; tais esclarecimentos são necessá-

\footnotetext{
${ }^{1}$ Não estudarei aqui as incompatibilidades entre a Escola de Cambridge e a Escola Neoclássica; a este respeito, ver Harcourt (1972).
} 
rios para entender a démarche de Keynes, mesmo se este autor afirma que o preço de oferta agregada "não deve ser confundido com o preço de oferta de uma unidade de produto (...)" (TG, p. 37). Marshall define o preço de oferta como “(...) o preço necessário para mobilizar o sacrifício para produzir qualquer quantidade dada de mercadoria (...)" (1982, volume I, p. 138). O preço de oferta constitui assim o preço que tem condições de propiciar uma remuneração "satisfatória" ao produtor desta mercadoria. O preço de demanda é “(...) o preço preciso para atrair compradores para qualquer quantidade dada de uma mercadoria (...)" (Idem); é o preço pelo qual o comprador tem interesse em comprar aquela mercadoria.

Por outro lado, na visão pós-keynesiana, a teoria de Keynes é uma teoria de escolha de ativos (Cardim, 1992, p. 168). Em função do retorno (real ou previsto), os agentes escolhem os ativos: moeda, ativos financeiros ou capital produtivo. A análise desenvolvida por Keynes na TG traduz este tipo de escolha: (a) o preço de oferta dá conta do retorno previsto do capital produtivo, a partir da eficiência marginal do capital (b) o preço de demanda traduz o retorno dos ativos financeiros, retorno este representado pela taxa de juros.

Keynes define o preço de oferta como "o preço que bastaria, exatamente, para induzir um fabricante a produzir uma nova unidade suplementar desse capital, (...) isto é, aquilo a que, por vezes, se chama custo de reposição" (TG, p. 115; proposição 1). Por outro lado, a eficiência marginal do capital é igual à taxa de desconto que "tornaria o valor presente do fluxo de anuidades das rendas esperadas desse capital (...) exatamente igual ao seu preço de oferta” (TG, p. 115; proposição 2). Enfim, trata-se do preço de oferta corrente do bem de capital, ou seja, do preço deste bem produzido no momento atual, e não do preço no momento em que ele foi comprado (proposição 3).

A partir da proposição 1, é possível afirmar que este preço corresponde à maximização do lucro esperado por parte dos capitalistas que produzem este bem de capital; a proposição 3 ressalta o fato que se trata de um custo de reposição, ou seja, que vai haver reavaliação do capital em função do período considerado; esta reavaliação se relaciona tanto com o valor do bem quanto com as receitas que ele pode gerar. A proposição 2 permite escrever a seguinte equação:

$$
P o=\frac{\Sigma R i}{(1+e)^{n}}
$$

$\left(\Sigma R i /(1+e)^{n}\right)$ representa o valor atualizado das expectativas de renda geradas pelo investimento, durante sua vida útil, Po o preço de oferta e $e$ a eficiência marginal do capital.

A equação (1) mostra que a eficiência marginal do capital depende de duas variáveis: as expectativas de longo prazo formuladas pelos empresários e o preço de oferta do capital. Quanto maiores essas expectativas, maior a eficiência marginal do capital, para Po dado; quanto maior o preço de oferta, menor esta eficiência, para $\Sigma R i$ dado. 
O preço de demanda é o valor corrente do retorno de determinado ativo financeiro, este valor sendo calculado à taxa de juros corrente $i$ (TG, p. 116):

$$
P d=\frac{\Sigma R i}{(1+i)^{n}}
$$

$\left(\Sigma \mathrm{Ri} /(1+\mathrm{i})^{\mathrm{n}}\right.$ representa o valor atualizado do retorno de determinado ativo e Pd o preço de demanda)

O raciocínio é feito em termos de valores esperados e, consequentemente, se relaciona com todo o período de utilização do bem de capital (TG, p. 117). Isto implica que o processo de produção capitalista seja concebido como um processo diacrônico no qual existem defasagens importantes. A partir do momento que existe incerteza, as variáveis reais não correspondem mais sistematicamente às realizadas e não há mais possibilidades concretas de maximizar uma função microeconômica de produção

O papel das expectativas e, mais especificamente, das expectativas de longo prazo, torna-se fundamental para explicar a maneira como os empresários tomam suas decisões ${ }^{3}$.

Uma determinação parcialmente endógena das expectativas de longo prazo: a consequência da refutação da Teoria dos Fundos de Empréstimos

A refutação da Teoria dos Fundos de Empréstimos (TFE) realizada por Keynes no capítulo XIV da TG pode ser sintetizada a partir das seguintes equações:

$$
\begin{aligned}
& \mathrm{I}=\varphi_{1}[\mathrm{e}-\mathrm{r}] \\
& \operatorname{com} \varphi_{1}{ }_{1}>0 \\
& \mathrm{Y}=\varphi_{2}(\mathrm{I}) \\
& \operatorname{com} \varphi_{2}>0 \\
& \mathrm{~S}=\varphi_{3}(\mathrm{Y}) \\
& \operatorname{com} \varphi_{3}>0
\end{aligned}
$$

(e representa a eficiência marginal do capital, $r$ a taxa de juros, I e $S$ respectivamente o investimento e a poupança, e $\mathrm{Y}$ a renda)

São três equações ${ }^{4}$ e quatro incógnitas, $e, r, I$ e $Y$; não é possível resolver este sistema. Como afirma Keynes, não é possível determinar simultaneamente, a partir

\footnotetext{
${ }^{2}$ Neste caso, é possível falar em microeconomia do desequilíbrio em um sentido próximo daquilo definido por Duménil e Lévy (1996).

${ }^{3}$ A este respeito ver, entre outros, Victoria Chick (1993, p. 17) e Kregel (1980).

${ }^{4}$ À medida que S depende de Y, é possível considerar, apenas, as equações (1) e (3); neste caso, são duas equações e três incógnitas: $e, r$ e Y. Da mesma maneira, não é possível resolver o sistema.
} 
deste sistema, a taxa de juros e a renda. Enquanto os clássicos exogeneizam o produto, Y, Keynes exogeneiza a taxa de juros, $r$.

i) A exogeneização de $r$ corresponde à endogeneização de e, ou seja, da eficiência marginal do capital. Em função da equação (1), isto significa que há uma endogeneização (parcial) das expectativas de longo prazo, $\Sigma \mathrm{Ri}$.

ii) Conforme demonstrarei neste trabalho, as flutuações econômicas são provocadas a partir de uma variação inicial exógena de $r$ : será, portanto, que a análise keynesiana explica os movimentos econômicos a partir de um choque exógeno da taxa de juros, e apenas estuda o impacto macroeconômico deste choque exógeno sobre o sistema?

A resposta é negativa, e isto pelas seguintes razões: há uma determinação exógena de $r$ no que diz respeito ao subsistema constituído pelas equações (3), (4) e (5). Não obstante, em nivel da arquitetura global do sistema proposto na TG, Keynes mostra claramente que r é determinado a partir da avaliação que os diferentes agentes fazem da incerteza: a taxa de juros é "a recompensa da renúncia à liquidez” (TG, p. 137), ou seja, da renúncia à segurança propiciada pela moeda. Por outro lado, esta preferência determina as variações de $r$ que permitem igualar oferta e demanda por moeda (Idem). Assim, $r$ é determinado a partir da preferência pela liquidez, preferência esta que traduz a avaliação que os agentes fazem da incerteza. A este respeito, certas análises pós-keynesianas enfatizam o papel das convenções nas modalidades de determinação da taxa de juros (Modenesi, Modenesi e Martins, 2012).

O mesmo procedimento é utilizado pelos economistas neorricardianos por um lado, no sistema sraffaiano, a taxa de salário é determinada exogeneamente; por outro lado, é possível explicar esta determinação da taxa de salário a partir das variáveis ligadas às instituições e/ou às convenções (Hodgson, 1985).

\section{A decisão de investimento: uma primeira análise}

A decisão de investimento se explica a partir da comparação entre a eficiência marginal do capital e a taxa de juros: enquanto a eficiência marginal do capital é superior à taxa de juros, vai haver investimento. Isto pode ser explicado, no nível microeconômico, pelas seguintes razões: se o empresário for comparar o retorno de um ativo financeiro e do investimento em capital fixo, este último apresenta um retorno maior.

Para certos autores, a diferença entre a eficiência marginal do capital e a taxa de juros tem que ser positiva: para Robinson (1983, p. 331), por exemplo, esta diferença representa um prêmio pelo risco ${ }^{5}$ inerente à decisão de investimento. Quanto maior este prêmio, maior será a propensão a investir; isto se justifica pelo fato de que as expectativas de longo prazo que determinam o investimento se relacionam com uma incerteza forte. Por outro lado, quanto maior a incerteza, maior este prêmio e maior a diferença entre $e$ e $i$ (Hansen, 1951, p. 130).

Num primeiro momento, Keynes considera que cada tipo de capital se carac-

\footnotetext{
${ }^{5}$ Ao pé da letra, a expressão prêmio pelo risco está errada: trata-se de incerteza, e não de risco.
} 
teriza por determina função, que se expressa por uma relação inversa entre o nível do investimento e a eficiência marginal do capital (TG, p. 116). Essas diferentes curvas de eficiência marginal do capital (ou de demanda por investimento) se caracterizam pelo fato de que a eficiência marginal do capital diminui quando o investimento aumenta.

No curto prazo, o aumento da demanda por capital faz com que seu preço de oferta aumenta (TG, pp. 115-116). Neste caso, a equação (1) mostra que a eficiência marginal do capital tem que diminuir, quando $\Sigma \mathrm{Ri}$ permanece constante. $\mathrm{O}$ equilíbrio de curto prazo se dá quando a eficiência marginal do capital se torna igual à taxa de juros; neste caso, o fluxo de capital novo se anula. O fluxo de investimento é positivo quando o preço de demanda é superior ao preço de oferta ${ }^{6}$, ou seja, quando a eficiência marginal do capital é superior à taxa de juros: é mais vantajoso realizar aquele investimento, o prêmio é positivo e os produtores de bens de capital vão aumentar sua produção.

No longo prazo, vai haver modificações das expectativas relativas às receitas geradas pelo investimento; o investimento antigo entrará em concorrência com o novo, este último permitindo produzir a preços menores (TG, p. 119). Isto se traduz por uma diminuição das receitas previstas, $S R i$; a equação (1) mostra que, para $P$ dado, $e$ diminui quando $\Sigma$ Ri diminui.

No modelo apresentado por Keynes, as expectativas de longo prazo são, pelos menos parcialmente, endógenas. Acredito que esta natureza parcialmente endógena do "choque" caracteriza as diferentes formas de heterodoxia: nas análises do mainstream, o choque é, por natureza, exógeno (Davidson, 1996); monetário, no que diz respeito às expectativas racionais, choque de produtividade (ou tecnológico) para a teoria dos ciclos reais, choque de demanda para os novos-keynesianos. Este tipo de análise estuda, apenas, os impactos deste choque sobre a economia; numa perspectiva heterodoxa, ao contrário, esta endogenia permite explicar a instabilidade estrutural do sistema (Vercelli, 1985).

A endogenia (pelo menos parcial) das expectativas de longo prazo é fundamental: é a partir das modificações das expectativas de longo prazo que a reavaliação do capital vai ser efetuada e que é possível explicar a produção endógena de flutuações.

\section{O mecanismo geral}

\section{O processo de agregação e as diferentes gerações de capital}

Uma análise dinâmica do processo é fornecida por Kregel (1980), a partir da utilização dos capitais de qualidade diferente. Vamos supor que $\mathrm{e}_{\mathrm{K} 1}>\mathrm{e}_{\mathrm{K} 2}>\ldots \ldots \ldots \ldots . . . \mathrm{e}_{\mathrm{Kn}}$. O processo ocorre da seguinte maneira:

\footnotetext{
${ }^{6}$ Davidson (1978, p. 70) fala em “ short-period flow-supply price”.
} 
$\left.\begin{array}{llll}\nearrow \mathrm{DK} 1 & \searrow \mathrm{e}_{\mathrm{K} 1} & \text { até } & \mathrm{e}_{\mathrm{K} 1}=\mathrm{e}_{\mathrm{K} 2} \\ \nearrow \mathrm{DK} 2 & \searrow \mathrm{e}_{\mathrm{K} 2} & \text { até } & \mathrm{e}_{\mathrm{K} 2}=\mathrm{e}_{\mathrm{K} 3}\end{array}\right\}$ sistema I

TDKn $\nu_{\mathrm{Kn}}$ até $\mathrm{e}_{\mathrm{Kn}}=\mathrm{i}$ (Dki representa a demanda por capital de qualidade $i$ )

$\mathrm{O}$ sistema alcança o equilíbrio quando $\mathrm{e}_{\mathrm{Kn}}$ se iguala com $\mathrm{i}$.

Keynes considera que, para cada tipo de capital, é possível determinar uma curva de eficiência marginal específica, e que a eficiência marginal da totalidade do capital é determinada pela mais alta dessas eficiências (TG, p. 115). Isto implica que, em determinado momento, vários capitais de gerações diferentes estejam presentes para oferecer um mesmo produto. A explicação, em relação à afirmação de Keynes, pode ser representada por meio do Gráfico I.

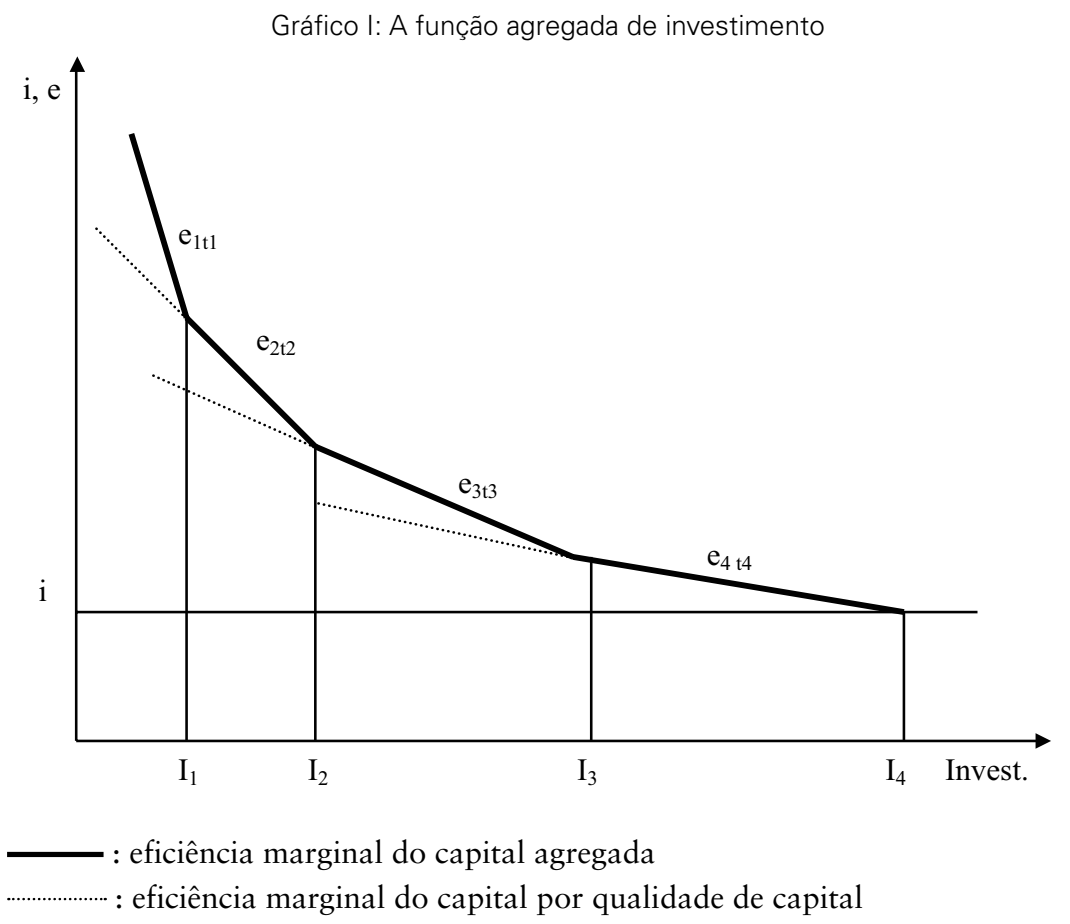

Vamos supor que existem quatro qualidades de capital pelas quais a eficiência marginal é superior ou igual à taxa de juros. No momento $t_{1}$, o investimento em capital de "melhor qualidade" $\left(\mathrm{K}_{1}\right.$, com a correspondente eficiência marginal $\left.e_{1}\right)$ vai aumentar até sua eficiência marginal se igualar com a eficiência marginal do capital de qualidade inferior $\left(\mathrm{K}_{2}\right.$ e $\left.e_{2}\right)$; da mesma maneira, uma vez esgotado o capital de melhor qualidade, a demanda pelo capital $\mathrm{K}_{2}$ vai aumentar até $\mathrm{e}_{2}$ diminuir e se igualar com a eficiência marginal do capital de qualidade inferior $\left(\mathrm{K}_{3}\right.$ e $\left.e_{3}\right)$. Por outro lado, houve uma reavaliação do capital $K_{1}$, no sentido de um queda de sua eficiência marginal, de tal maneira que esta se iguale com aquela do capital $K_{2}$; isto 
corresponde a uma modificação das expectativas relativas ao retorno do capital $\mathrm{e}_{1} \mathrm{t}_{1}$, no longo prazo. Em $\mathrm{t}_{2}$, temos que $\mathrm{e}_{1} \mathrm{t}_{1}=\mathrm{e}_{2} \mathrm{t}_{2}$; como a demanda pelo capital $\mathrm{K}_{2}$ continua aumentando, o mesmo processo se repete, até $e_{2} t_{2}$ se igualar com $e_{3} t_{3}$. Este processo se repete até a eficiência marginal do capital se igualar com a taxa de juros.

A complexidade do processo global provém do fato de que, para cada período, está tendo uma reavaliação das expectativas que se relacionam com o tipo de capital que, no período anterior, apresentava a eficiência marginal mais alta. É por isto que a eficiência do capital global é determinada a partir da maior eficiência; só que esta maior eficiência se modifica com o decorrer do tempo, o que implica investir em capital de "qualidade inferior". É isto que Keynes quis dizer quando afirma que "A produção obtida com o equipamento fabricado hoje terá de competir (...) com a o equipamento fabricado mais tarde com uma técnica melhor (...) (TG, p. 119). Está tendo uma atualização do investimento realizado no passado em função das condições atuais de remuneração do capital.

É possível estabelecer um paralelo entre este procedimento e o de Ricardo e de $\mathrm{Sraffa}^{7}$, no que concerne às quantidades de trabalho passado; neste procedimento, o trabalho passado é reavaliado em função das condições que prevalecem hoje, ou seja, em função da taxa de lucro atual. Existe igualmente uma semelhança metodológica entre este procedimento e o empregado por Ricardo no que diz respeito à teoria da renda diferencial: as terras de diferente qualidade são reavaliadas, a cada período, em função das condições atuais.

Este mecanismo corresponde à seguinte afirmação de Rotheim (1998, p. 370): “(...) recent research (...) have shown that Keynes understood diminishing marginal productivity to occur only because of a heterogeneous stock of capital, which had constant returns for any vintage, but whose returns diminished as the margin of utilization spreads to less efficient vintage”. A única diferença entre minha interpretação e a interpretação de Rotheim provém do fato de que, na minha interpretação, o retorno de cada geração (vintage) de capital é decrescente, e não constante. O retorno constante evocado por Rotheim corresponde à teoria da renda diferencial de Ricardo.

\section{Equilíbrios de estoque e equilíbrio de fluxos}

Keynes define quatro conceitos (TG, p. 177 e seguintes):

q representa o rendimento de determinado ativo;

c, o custo de manutenção em termos de si mesmo; este custo se relaciona diretamente com o desgaste do bem, independentemente de sua utilização;

1, o prêmio de liquidez. Este se relaciona com a segurança proporcionada pela posse deste bem.

a, a porcentagem de valorização (ou de depreciação) do bem

\footnotetext{
${ }^{7}$ No que diz respeito a Ricardo, tal procedimento é implementado no primeiro capítulo de Princípios de Economia Política e Tributação; Sraffa procede da mesma maneira quando ele efetua a redução a quantidades datadas de trabalho (1977, p. 51).
} 
Os "poupadores" estão interessados em comparar o retorno dos diferentes ativos, incluindo a moeda e os ativos financeiros, bem como no fato de ter uma certa segurança.

Os bens duráveis de capital (Keynes fala em capital instrumental ou capital de consumo) apresentam as seguintes características: seus rendimentos excedem seu custo de manutenção e o prêmio de liquidez é muito baixo. A eficiência marginal desses bens diminui com o aumento de sua produção e de sua demanda. Não obstante, sua elasticidade de produção é positiva; a um aumento de sua produção corresponde um aumento da quantidade total de trabalho utilizado. A moeda apresenta características diferentes: seu custo de manutenção é desprezível, seu rendimento também, mas seu prêmio de liquidez é alto. Ela possui elasticidade de produção igual a zero; o aumento de sua produção não implica um aumento da quantidade de trabalho. A este respeito, é interessante observar que esta concepção é incompatível com a existência de uma moeda mercadoria (Cardim, 1986). Sua elasticidade de substituição é igualmente igual a zero; em função dos diferentes elementos que permitem explicar a preferência pela liquidez, quando seu valor sobe, ela não vai ser substituída por outros ativos. De fato, isto pode ser explicado a partir de sua função de reserva de valor diante da incerteza que caracteriza este universo econômico. Contrariamente aos bens duráveis, sua eficiência marginal não diminui com sua produção. Finalmente, a moeda tem um rendimento e um custo de manutenção praticamente iguais a zero $(q=c=0)$, mas um prêmio de liquidez elevado.

A partir desta análise, o equilíbrio, em termos de estoques, vai ser alcançado quando os rendimentos de todos os ativos se igualam com a taxa de juros (Kregel, 1980, p. 41): quando o fluxo de capital se torna igual a zero, o nível do estoque de capital permanece constante ${ }^{8}$. É possível ilustrar este processo a partir do seguinte exemplo: vamos considerar três ativos, cujos retornos esperados são os seguintes:

B1: $\mathrm{a} 1+\mathrm{q} 1$

B2: $\mathrm{a} 2+\mathrm{q} 2$

B3: 13

(De fato, B1 e B2 representam bens não monetários; seu prêmio de liquidez é igual a zero e sua eficiência marginal diminui com sua demanda. B3, ao contrário, representa a moeda)

No estado de equilíbrio, o retorno esperado desses três bens será igual (TG, p. 179):

$\mathrm{a} 1+\mathrm{q} 1=\mathrm{a} 2+\mathrm{q} 2=13(6)$

Em função do que chamamos as diferentes qualidades de capital, os poupadores vão investir, sucessivamente, em cada um desses tipos de capital até a efi-

\footnotetext{
${ }^{8}$ Para simplificar este raciocínio, consideraremos que não há depreciação do capital existente.
} 
ciência do capital total se igualar com a taxa de juros, ou seja, com 13. Se partirmos de uma posição inicial de equilíbrio, e da hipótese segundo a qual a taxa de juros é constante durante este processo, é preciso analisar as implicações ligadas a uma diferença entre Pd e Po. Vamos supor que Pd > Po, o que gera, no curto prazo, um investimento. A partir da definição do preço de oferta, é possível assimilar a1 e a2 a este mesmo preço: no curto prazo, a1 e a2 vão aumentar, ou seja, o preço de oferta aumenta. Enquanto Pd > Po, o fluxo de investimento é positivo, o equilíbrio, em termos de estoques, não é realizado. O equilíbrio de curto prazo (equilíbrio de fluxo) é alcançado se o aumento de Po é suficiente para que $\mathrm{Po}=\mathrm{Pd}$.

No longo prazo, a partir da equação (6), é possível deduzir que q1 e q 2 vão diminuir, o que permite alcançar, de novo, o equilíbrio de longo prazo (equilíbrio de estoque).

\section{CURTO PRAZO}

$\mathrm{Pd}>\mathrm{Po} \Rightarrow \lambda \mathrm{Dk} \Rightarrow \lambda \mathrm{a}_{1}$ e $\lambda_{\mathrm{a}_{2}} \Rightarrow \lambda \mathrm{Po}$

O equilíbrio de fluxos é alcançado se Pd $=$ Po (4)

$O$ equilíbrio de estoque não é realizado: $\mathrm{a}_{1}+\mathrm{q}_{1} \neq \mathrm{a}_{2}+\mathrm{q}_{2} \neq \mathrm{l}_{3}(5)$

LONGO PRAZO

O sistema alcança o equilíbrio de estoque: $\forall q_{1}$ e $\forall q_{2} \Rightarrow a_{1}+q_{1}=a_{2}+q_{2}=l_{3}$ (3)

O equilíbrio de fluxos não é realizado: $\forall \mathrm{q}_{1}$ e $\forall \mathrm{q}_{2} \Rightarrow \forall \mathrm{e}_{1}$ e $\forall \mathrm{e}_{2} \Rightarrow \lambda \mathrm{Po} \Rightarrow \mathrm{Po}>\mathrm{Pd}$ (6)

Segundo Asimakopulos (1991, p. 106), o equilíbrio em termos de estoque não implica, obrigatoriamente, o equilíbrio em termos de fluxos. Neste caso, se as variações de Po são tais que elas verificam as relações do Quadro I, vai haver instabilidade do equilíbrio de longo prazo, ou seja, do equilíbrio de estoque ${ }^{9}$. As variações do investimento explicam as flutuações econômicas; (a) haveria equilíbrio em todos os pontos do tempo se houvesse, simultaneamente, equilíbrio de estoque e de fluxos. A não verificação desta condição permite explicar as flutuações econômicas (b) apenas a realização deste equilíbrio contínuo implicaria que as expectativas sejam plenamente realizadas ${ }^{10}$.

\footnotetext{
${ }^{9}$ Hansen (1951., p. 342): “(...) o crescimento esporádico do capital é tudo que precisa para produzir ciclos (...)".

${ }^{10}$ A respeito desses dois últimos pontos, ver John Hicks (1965, pp. 89 e 93).
} 


\section{A ECONOMIA DE KEYNES: ESTRUTURA DO MODELO, NATUREZA DO CAPITAL E CONDIÇÕES SOCIAIS DE VALORIZAÇÃO}

\section{Estrutura comparada dos modelos keynesiano e neo-ricardiano}

\section{A agregação do capital na TG: uma primeira análise}

Keynes era plenamente consciente das dificuldades teóricas relativas à avaliação e à medida dos principais agregados (principalmente a produção nacional e a quantidade total de capital) e de suas evoluções. A este respeito, ele fala “(...) no fato de a produção da comunidade em bens e serviços ser um complexo não homogêneo que não se pode medir (...)", (TG, p. 48). Encontramos aqui a problemática neo-ricardiana relativa à agregação, em valor, de capitais heterogêneos.

Keynes propõe de medir as “(...) mudanças da produção corrente com referência ao número de horas de trabalho pagas e aplicadas no equipamento existente (...) ponderando as horas de trabalho qualificado de acordo com sua remuneração. (TG, p. 51).

Apesar de não raciocinar nos mesmos termos que Ricardo e Sraffa, ou seja, em termos de trabalho datado, Keynes adota a quantidade de trabalho para medir a produção e o capital. Seguindo os economistas clássicos, principalmente Smith, Ricardo e Marx, ele mostra que, a partir da redução do trabalho complexo em trabalho simples, é possível adotar a hipótese da homogeneidade do trabalho (Idem, p. 50); por exemplo, uma hora de trabalho qualificada será igual a $x$ horas de trabalho simples ( $x$ sendo superior a 1$)$. Esta quantidade será expressa em unidades de salário.

O fato de Keynes medir as variações do produto e do capital a partir das quantidades de trabalho se explica a partir (a) da impossibilidade de agregar, em valor, bens (de consumo e de capital) não homogêneos, e (b) do fato de considerar que o salário monetário constitui uma unidade de medida adequada e homogênea comum ao conjunto desses bens.

\section{Taxa de juros e estrutura dos modelos}

No modelo neoclássico, a taxa de juros natural de Wicksell, por exemplo, “(...) corresponde ao rendimento que se espera obter do capital de nova produção (...)" e iguala demanda de capital e oferta de poupança (Wicksell, 1997, p. 256). Neste sentido, ela é concebida como uma variável real e não monetária, em um universo no qual não há incerteza.

A controvérsia de Cambridge ${ }^{11}$ relativa à agregação e à mensuração do capital ressalta o fato de que, neste procedimento, o capital é avaliado independentemente da taxa de juros; em outras palavras, não está tendo reavaliação da quantidade

\footnotetext{
${ }^{11}$ Para uma apresentação desta problemática, ver Cohen e Harcourt (2003).
} 
de capital nos diferentes períodos. Isto é totalmente diferente do método proposto por Keynes e por Sraffa, e pode ser explicado pela necessidade lógica de definir a taxa de lucro (de juros) a partir de variáveis reais. Novamente, está colocado o problema da mensuração, em valor, de uma quantidade de capital agregada composta por capitais heterogêneos. Keynes era totalmente consciente da impossibilidade lógica de implementar tal método: “ (...) a tentativa de derivar a taxa de juros da eficiência marginal do capital está errada (...) pelo fato desta depender da escala do investimento corrente e de precisar conhecer já a taxa de juros antes de poder calcular esta escala" ${ }^{12}$.

\section{As convergências com a economia clássica}

\section{Um paralelo com a teoria da renda diferencial de Ricardo}

As modalidades de atualização do investimento realizado no passado combinam dois procedimentos utilizados por Ricardo: aquilo que se relaciona com a atualização do trabalho passado e aquilo expresso na teoria da renda diferencial.

Ricardo considera que o capital fixo é constituído pelo trabalho gasto no passado; assim, é possível expressar o valor relativo de determinada mercadoria pela quantidade total de trabalho direto e indireto. Não obstante, quais são as modalidades utilizadas por Ricardo para avaliar o trabalho gasto no passado, sob a forma de capital fixo (Ricardo, 1983, p. 53)? Ricardo atualiza o trabalho gasto no passado a partir do valor atual da taxa de lucro e da taxa de salário que lhe corresponde. Em cada período, o trabalho passado é reavaliado em função das condições atuais.

Keynes adota um mecanismo semelhante, em cada ponto do tempo, para reavaliar a eficiência marginal dos capitais de qualidade diferente. A eficiência marginal do capital global, conforme afirma Keynes, é determinada pela maior eficiência dos diferentes tipos de capital, esta sendo reavaliada em função das condições atuais. Neste esquema, a reavaliação da eficiência marginal do capital, em geral, cumpre o mesmo papel que a renda diferencial de Ricardo:

i) ela permite igualar, em cada ponto do tempo, a eficiência marginal dos capitais de diferente qualidade; da mesma maneira, no modelo ricardiano, a renda crescente da terra permite igualar a taxa de lucro no setor agrícola (Idem, p. 67). Este processo de reavaliação permite definir a mesma eficiência para as diferentes qualidades de capital, em cada instante;

ii) em um determinado momento, o poupador vai investir no capital de "melhor qualidade" naquele momento. Este, a partir do momento que sua eficiência

\footnotetext{
12 J. M. Keynes, The Collected Writtings of J. M. Keynes, London, Macmillan, 1973, XIV p. 477.
} 
marginal é superior ou igual à taxa de juros, representa a melhor oportunidade de investimento.

$\mathrm{Na}$ análise de Ricardo, o lucro obtido é reavaliado de maneira descontínua, e se modifica a cada período. O equilíbrio é alcançado pelo fato de haver igualação da taxa de lucro dos capitais investidos nas diferentes terras; a tendência à queda da taxa de lucro explica-se a partir da produtividade marginal decrescente da terra, ou seja, a partir da escassez da terras de melhor qualidade.

Quadro II: Uma comparação Keynes/Ricardo

\begin{tabular}{|c|c|}
\hline Ricardo & Keynes \\
\hline $\begin{array}{l}\mathrm{t}_{1} \mathrm{~L}_{1} \\
\mathrm{t}_{2} \mathrm{~L}_{2}=\mathrm{L}_{1}-\mathrm{R}_{12} \\
\mathrm{t}_{3} \mathrm{~L}_{3}=\mathrm{L}_{1}-\mathrm{R}_{13} \\
\quad=\mathrm{L}_{2}-\mathrm{R}_{23}\end{array}$ & $\begin{array}{l}\searrow \mathrm{e}_{1 \mathrm{t} 1} \text { até } \mathrm{e}_{1 \mathrm{t} 1}=\mathrm{e}_{2} \\
\forall \mathrm{e}_{2 \mathrm{t} 2} \text { até } \mathrm{e}_{2 \mathrm{t} 2}=\mathrm{e}_{3} \\
\mathrm{e}_{3 \mathrm{t} 3} \text { até } \mathrm{e}_{3 \mathrm{t} 3}=\mathrm{e}_{4}\end{array}$ \\
\hline $\begin{aligned} \operatorname{tn} \mathrm{Ln} & =\mathrm{L}_{1}-\mathrm{R}_{1 \mathrm{n}} \\
& =\mathrm{L}_{2}-\mathrm{R}_{2 \mathrm{n}} \\
& =\mathrm{L}_{\mathrm{n}-1}-\mathrm{R}_{\mathrm{n}-1 \mathrm{n}}\end{aligned}$ & $\forall \mathrm{e}_{\mathrm{ntn}}$ até $\mathrm{e}_{\mathrm{ntn}}=\mathrm{i}$ \\
\hline
\end{tabular}

$\left(\mathrm{L}_{1}, \mathrm{~L}_{2} \ldots \mathrm{L}_{\mathrm{n}}\right.$ representam o lucro obtido sobre as terras de qualidade diferente; $\mathrm{R}_{\text {in }}$, a renda diferencial aplicada na terra i no período $\mathrm{n}$ )

O conceito de escassez definido por Keynes é diferente daquele utilizado por Ricardo: Keynes define a escassez como a razão que explica o fato de o capital ter um rendimento superior ao seu custo e à taxa de juros (TG, p. 169); não obstante, esta escassez não corresponde à lei da produtividade marginal decrescente à medida que esta queda da eficiência marginal do capital não se explica a partir do fato dele ser menos produtivo, em termos físicos (Idem), ou seja, em termos reais.

\section{Ciclo econômico e escassez de capital.}

O conceito de escassez, e consequentemente de abundância, de capital, está presente na economia clássica: Adam Smith, por exemplo, a define da seguinte maneira: "À medida que cresce o capital de qualquer país, reduzem-se necessariamente os lucros que é possível obter com seu emprego" (1980, p. 615). Em seguida ele mostra que, a esta abundância de capital, corresponde uma escassez do trabalho, a qual faz subir os salários e diminuir o lucro: (a) esta abundância de capital, e a queda da taxa de lucro correspondente, se devem às condições de valorização social do capital, e não às condições técnicas (b) existe uma relação entre o valor da taxa de lucro e o da taxa de juros (Idem, p. 212). 
Na TG, o ciclo econômico se explica a partir das variações cíclicas da eficiência marginal do capital: a escassez (ou a abundância) relativa do capital explica a alternância entre fases de expansão e de recessão (TG, pp. 243 e 245); Keynes fornece, assim, elementos para construir uma teoria das flutuações econômicas. $\mathrm{O}$ conceito de abundância de capital leva, do ponto de vista lógico, a definir situações de sobreinvestimento (TG, p. 248); essas flutuações são ampliadas pelas modificações das expectativas no sentido de uma queda devida ao pessimismo ambiente (TG, p. 249).

Esta argumentação utiliza elementos que provêm do Treatise on Money: nesta obra, Keynes afirma que um excesso de poupança corresponde a uma situação na qual o lucro dos empresários é, de fato, inferior ao lucro normal (TG, p. 74). Ele chega a construir a seguinte função de lucro: $L=I-P, L$ representando o excesso de lucro em relação ao lucro normal. Se $\mathrm{P}>\mathrm{I}$, temos que $\mathrm{L}<0$, o que caracteriza uma fase de recessão; se $\mathrm{P}<\mathrm{I}$, L será superior a 0 , o que caracteriza uma fase de expansão. O lucro normal se define a partir da taxa de lucro que, se for realizada, não incitaria os empresários a modificar sua escala de produção $(\mathrm{TG}, \mathrm{p} .125)^{13}$. Durante a fase de recessão aparecem processos que vêm diminuir esta abundância de capital ${ }^{14}$ e permitem restaurar uma escassez relativa; da mesma maneira, durante a fase de expansão aparecem elementos que vêm progressivamente diminuir esta escassez. Keynes afirma que o auge da fase de expansão caracteriza-se pelo sobreinvestimento, o qual explica a queda próxima da eficiência marginal do capital; nesta fase, as expectativas “otimistas” são destinadas a malograr (TG, p. 248).

Finalmente, não é possível deixar de estabelecer um paralelo entre as variações da eficiência marginal do capital, no decorrer do ciclo, e a análise de Marx: (a) o próprio conceito de escassez e abundância de capital não se relaciona com uma diminuição da produtividade "física" do trabalho, mas sim com a razão entre o capital e a mais-valia realizada. A este respeito, Marx fala em sobre acumulação e em sobre produção de capital (1976, p. 269): (b) a depreciação periódica de parte do capital social, em Marx, corresponde aos elementos presentes no capítulo 22 da TG: “(...) o ciclo econômico deve, de preferência, ser considerado como o resultado de uma variação cíclica na eficiência marginal do capital (...)" (TG, p. 243; o grifo é meu). Assim, as flutuações econômicas podem ser explicadas de uma maneira endógena; a alternância entre expansão e recessão provém da escassez ou da abundância relativa de capital em relação às suas condições de valorização social ${ }^{15}$.

\footnotetext{
${ }^{13}$ Esta definição foi utilizada por Harrod para definir a taxa de crescimento garantida (1939).

${ }^{14}$ A este repeito, Marx (1976, Livro III, p. 269) analisa diferentes modalidades de desvalorização do capital social, entre outras a "queima" de parte deste capital.

${ }^{15}$ Para uma formalização deste argumento, ver Herscovici (2002, p. 299 e seguintes).
} 


\section{A contribuição de Sraffa: a ausência de equilíbrio de longo prazo}

Os resultados da escola neorricardiana são os seguintes: (a) uma resolução formal do problema da transformação, resolução efetuada a partir de uma abordagem clássica (b) uma determinada concepção da natureza do capital agregado. No âmbito de uma análise dinâmica, o primeiro resultado é pouco utilizável enquanto, ao contrário, o segundo é de primeira importância: é a partir deste último que estudarei as convergências entre Keynes e Sraffa, ou seja, o papel das variáveis distributivas e suas relações intrínsecas com a instabilidade do sistema ${ }^{16}$.

Sheila Dow (1985, pp. 125-126) afirma que, na TG, existem três temporalidades diferentes: o tempo lógico, que permite explicitar as relações causais, o tempo bistórico que corresponde à existência da incerteza e das instituições que permitem contê-la, e, finalmente, o tempo "expectacional" que dá conta das relações entre o comportamento individual e os determinismos macrossociais e econômicos. A partir de tal perspectiva, a análise de Sraffa em termos de preços de produção e de posição de longo prazo utiliza, apenas, o tempo lógico e não pode ser desenvolvida em termos de tempo histórico e expectacional; neste sentido, o conceito sraffaiano de preço de produção não pode ser integrado numa perspectiva dinâmica.

De modo geral, os resultados da controvérsia de Cambridge são incompatíveis com a existência de uma posição de longo prazo que se caracteriza pelo fato de a quantidade de capital agregada ser constante, em valor. Assim, "Long-period equilibria cannot be determined, because the datum relative to the endowment of "capital' is logically indeterminable" (Petri, 1998, p. 17). Este equilíbrio é indeterminado pelo fato de o valor do capital mudar em função da mudança das variáveis distributivas, mudança esta gerada pelo próprio processo de ajustamento; estamos na presença de path dependence. A instabilidade será explicada a partir deste mecanismo: o modelo de Harrod e, de maneira mais geral, todos os modelos keyenesianos (não neoclássicos) chegam a resultados semelhantes e apontam para desequilíbrios cumulativos (Herscovici, 2002).

\section{TFE e convergências entre Keynes e Sraffa}

A Teoria dos Fundos de Empréstimo (TFE) permite determinar, endogenamente, a taxa de juros a um nível que corresponde ao pleno emprego (a taxa natural de Wicksell), e verificar a lei de Say, na medida em que, indiretamente, a parte da renda que não é gasta em consumo, será gasta em investimento.

O capítulo XIV da TG constitui um momento importante da crítica keynesiana aos "clássicos": Keynes mostra, a este respeito, que a taxa de juros tem que ser determinada exogenamente (Vercelli, 1991, p. 184). Nada indica que, em função da

${ }^{16}$ Ver Harris (1978, p. 162 e seguintes). 
determinação exógena da taxa de juros, o equilíbrio assim realizado corresponda a uma situação de pleno emprego; este procedimento ressalta uma determinação monetária da taxa de juros, em função da relação que a moeda tem com a incerteza.

$\mathrm{O}$ instrumental neorricardiano permite formular o mesmo tipo de resultado. No âmbito da macroeconomia walrasiana, é a flexibilidade da taxa de juros que permite explicar a convergência para o equilíbrio: qualquer excesso de demanda (oferta) por fundos será eliminado a partir de um aumento (diminuição) da taxa de juros. Na perspectiva neorricardiana, este mecanismo não pode atuar, e isto pelas seguintes razões:

(a) a controvérsia de Cambridge mostra explicitamente que não há uma relação monotônica entre a taxa de juros e a quantidade agregada de capital, em valor: assim, nada garante que a variação da taxa de juros permita voltar ao equilíbrio.

(b) Por outro lado, a existência de um equilíbrio estável é incompatível com os resultados neorricardianos: a existência de uma quantidade agregada de capital, cujo valor é independente do valor das variáveis distributivas, não pode ser verificada. Por natureza, este equilíbrio de longo prazo é indeterminado (Petri, 1998, p. 14).

\section{A instabilidade em Keynes}

É possível encontrar o mesmo tipo de relações na TG: a ausência de relação monotônica entre a taxa de juros e a razão K/L, e a ausência de correlação negativa entre a taxa de juros e a quantidade de capital agregada.

Os elementos da TG permitem escrever o sistema seguinte:

$$
\begin{aligned}
& \mathrm{I}=\varphi_{1}(\mathrm{e}-\mathrm{r}), \operatorname{com} \varphi_{1}^{\prime}>0 \\
& \Delta \mathrm{Y}=\Delta \mathrm{L}=1 / \mathrm{s} \cdot \Delta \mathrm{I} \\
& \mathrm{e}=\varphi_{2}(\mathrm{I}), \operatorname{com} \varphi_{2}^{\prime}<0 \\
& \mathrm{I}=\varphi_{1}\left[\varphi_{2}(\mathrm{I})-\mathrm{r}\right]
\end{aligned}
$$

( $s$ representa a propensão marginal a poupar, e $\mathrm{L}$ a quantidade total de trabalho)

Por um lado, o investimento depende da diferença entre a eficiência marginal do capital e a taxa de juros. Por outro, a eficiência marginal do capital depende do estoque de capital; sob certas condições, o sistema pode produzir, de maneira endógena, flutuações econômicas.

i) Podemos supor que haja uma queda exógena da taxa de juros. Esta hipótese corresponde à perspectiva da TG, e se explica a partir das modificações da avaliação que os agentes fazem da incerteza. A equação (7) mostra que à queda da taxa de juros corresponde um aumento do investimento; a equação (8) mostra que, a partir do multiplicador keynesiano, o aumento da renda e da quantidade de trabalho é maior que o aumento de $\mathrm{K}^{17}$ : assim, $\mathrm{K} / \mathrm{L}$ diminui, contrariamente ao que afirma a teoria neoclássica.

ii) Em função de (9), podemos deduzir que $e$ diminui; o impacto sobre o inves-

\footnotetext{
${ }^{17}$ As afirmações feitas no capítulo 4 da TG implicam que haja proporcionalidade entre Y e L.
} 
timento depende da diferença entre $e$ e $r$. O investimento só aumentará se $(e-r)$ for aumentar, ou seja, se a queda da taxa de juros for maior que a queda da eficiência marginal do capital. Se, ao contrário, a queda de $r$ for menor que a queda de $e$, haverá diminuição do investimento.

iii) Essas relações ressaltam mecanismos de instabilidade, a partir de variações exógenas da taxa de juros $r$. Um aumento de $r$ se traduz por uma diminuição do investimento, ou seja, por um aumento de $e$; se o aumento de $r$ for superior ao aumento de $e$, o investimento diminui, o que gera um processo cumulativo de recessão. Da mesma maneira, uma diminuição de $r$ gera um aumento do investimento, o qual se traduz por uma queda de $e$; se a queda de $e$ for inferior à queda de $r$, há um processo cumulativo de expansão. Nessas condições, as flutuações são endógenas.

iv) Finalmente, é possível ressaltar os limites dessas flutuações, ou seja, a existência de pontos de reversão (turning points). Numa fase de expansão, por exemplo, o aumento do investimento gera uma queda de $e$; esta queda depende do aumento do estoque de capital. Obrigatoriamente, chega um ponto no qual a queda de $e$ será superior à queda de $r^{18}$, o que implica uma recessão, e a restauração progressiva de $e$.

Finalmente, podemos afirmar que (a) não há uma relação linear entre i e $\mathrm{K} / \mathrm{L}^{19}$, o que é um resultado neorricardiano, (b) que as relações existentes na TG permitem explicar a produção endógena de flutuações e (c) que essas relações permitem igualmente explicar as reversões de tendência (TG, p. 248).

Se introduzimos defasagens na equação (10), em função do valor dos parâmetros, ela pode gerar movimentos caóticos.

\section{CONCLUSÃO}

Um dos elementos unificador e inovador da TG é a concepção relativa à natureza do capital: ela permite refutar a análise clássica, segundo os termos utilizados por Keynes, e constitui assim um dos fundamentos da ruptura metodológica e do surgimento de um paradigma alternativo. Neste sentido, há uma continuidade metodológica e epistemológica entre as intuições keynesianas e os trabalhos de Sraffa e dos economistas neorricardianos: a partir da controvérsia de Cambridge e de seus desdobramentos, essas problemáticas foram sistematizadas e generalizadas. Esta perspectiva permite ir além das oposições tradicionais entre (pós-) keynesianos e neorricardianos, e construir um paradigma comum.

No âmbito deste paradigma alternativo, o papel das instituições é de primeira importância: do ponto de vista da construção da macroeconomia keynesiana e neorricardiana, conforme visto, existe uma determinação exógena das variáveis

\footnotetext{
18 É possível supor que existe um valor mínimo da taxa de juros.

${ }^{19}$ Pasinetti (1997) formula um resultado semelhante.
} 
distributivas: a taxa de juros, no caso keynesiano, a taxa de lucro ou a taxa de salário, no caso neorricardiana ${ }^{20}$. Neste caso, o papel das instituições é fundamental nas modalidades de determinação dessas variáveis. Por outro lado, essas variáveis institucionais permitem limitar a amplitude das flutuações geradas pela instabilidade estrutural do sistema, e atuam assim como variáveis reguladoras.

Finalmente, este paradigma fornece uma explicação endógena das flutuações e dos movimentos econômicos, sem ter que invocar um choque, por natureza exógeno. Este último ponto constitui, a meu ver, um passo importante na tentativa de construção de uma análise especificamente dinâmica.

\section{REFERÊNCIAS BIBLIOGRÁFICAS}

Amadeo Edward J, Dutt Amitava Krisna, 1987, Os keynesianos neorricardianos e os pós-keynesianos, Pesquisa e Planejamento, 17 (3), dez. 1987.

Asimakopulos, A., 1991, Keynes's general theory and accumulation, Modern Cambridge Economics, Cambridge University Press, Cambridge.

Carvalho, Fernando Cardim de, 1986, “A teoria monetária de Marx: uma interpretação pós-keynesiana”, Revista de Economia Política, vol. 6, n. 4, outubro-dezembro 1986, São Paulo.

, 1992, Moeda, produção e acumulação: uma perspectiva pós-keynesiana, Moeda e produção: Teorias comparadas, Editora UnB, Brasília.

Chick, Victoria, 1993, Macroeconomia após Keynes. Um reexame da Teoria geral, Forense Universitária, Rio de Janeiro.

Cohen Avi J., Harcourt G.C., 2003, Whatever Happened to the Cambridge Capital Theory Controversies?, in Journal of Economic Perspectives - Volume 17, Winter 2003.

Davidson, Paul, 1978, Money and the real world, Macmillan Press, London. , 1996, Reality and economic theory”, Journal of Post Keynesian Economics, Summer 1996.

Dow Sheila C., 1985, Macroeconomic Thought. A Methodological Approach, Basil Blackwell, Oxford.

Duménil Gérard, Lévy Dominique, 1996, La dynamique du capitalisme. Un siècle d'économie américaine, Actuel Marx/PUF, Paris.

Hansen, Alvin H. 1951, Business Cycles and National Income, W.W. Norton \& Company. New York.

Harcourt, G.C., 1972, Some Cambridge Controversies in the Theory of Capital, Cambridge University Press, Cambridge.

Harris, Donald, Capital 1978, Accumulation and Income Distribution, Standford University Press, Stanford, California.

, 1988, “On the classical theory of competition", Cambridge Journal of Economics, 139-167.

Harrod, Roy F., 1939, An Essay in Dynamic Theory, The Economic Journal.

Herscovici, Alain, 2002, Dinâmica macroeconômica: uma interpretação a partir de Marx e de Keynes, EDUFES/EDUC, São Paulo.

,2006, Keynes e a teoria dos fundos de empréstimos:os fundamentos da crítica de Keynes à economia (neo) clássica., Análise Econômica, ano 24, n. 46, setembro 2006, Faculdade de Ciências Econômicas, UFRGS, Porto Alegre.

Hicks, John, 1965, Capital and Growth, Oxford University Press, London.

\footnotetext{
${ }^{20}$ Hodgson (1985, p. 175), por exemplo, mostra que o salário não é determinado a partir da demanda e da oferta de trabalho, mas a partir de certas convenções e instituições sociais. Certos autores pós-keynesianos enfatizam o papel das convenções no que diz respeito à determinação da taxa de juros (Modenesi, Modenesi e Martins, 2012).
} 
Hodgson, Geoffrey M., 1998, The Approach of Institutional Economics, Journal of Economic Literature, Volume 36, Issue 1, March 1998.

Keynes, John Maynard, 1990, A teoria geral do emprego, do juro e da moeda, Atlas, São Paulo, 1990. 1973, The Collected Writtings of J. M. Keynes, London, Macmillan.

Kregel, J. A, 1980, “Markets and institutions as features of a capitalistic production system”, Journal of Post-keynesian Economics, Fall 1980, vol. III n. 1.

Marshall, Alfred, 1982, Princípios de Economia, Abril Cultural, São Paulo, 1982, vol. I.

Marx, Karl, 1976, Le Capital, Critique de l'économie politique, Editions Sociales, Paris, Livro III.

Modenesi A., Modenesi R., Martins N., 2012, Convention, Interest Rates and Monetary Policy: a post-Keynesian-French-conventions-school approach, V Encontro da AssociaçãoKeynesiano Brasileira, São Paulo.

Pasinetti, Luigi L., 1997, The marginal efficiency of Investment, A "Second Edition" of the General Theory-Vol. 1, Edited by G.C. Harcourt and P.A. Riach, Routledge, 198-218.

Petri Fabio, 1998, The "Sraffian" critique of neoclassical economics: some recent developments, Revista da Sociedade Brasileira de Economia Política n, 3, dezembro de 1998, Rio de Janeiro.

Ricardo, David, 1982, Princípios de Economia Política e Tributação, Abril Cultural, São Paulo.

Robinson, Joan, 1983, Ensaios sobre a teoria do Crescimento Econômico, Os Economistas, São Paulo.

Rotheim Roy J, 1988, Keynes and the marginalist thepry of distribution, Journal of Post Keynesian Economics, Spring 1988, vol. 20, n.3, 355-387.

Smith, Adam, 1980, Inquérito sobre a natureza e as causas da riqueza das nações, Fundação Calouste Gulbenkian, Lisboa, vol I.

Sraffa Piero, 1977, Produção de mercadorias por meio de mercadorias. Prelúdio a uma Crítica da Teoria Econômica, Zahar Editores, Rio de Janeiro.

Vercelli, Alessandro, 1985, “ Keynes, Schumpeter, Marx and the srtuctural instability of capitalism”, L’hétérodoxie dans la pensée économique, G. Deleplace, P. Maurisson org., Cahiers d'Economie Politique, Anthropos, Paris. 1991, Methodological foundations of macroeconomics: Keynes after Lucas, Cambridge University Press, Cambridge.

Wicksell, Knut, 1987, “Lições de Economia Política” in Os clássicos da Economia, Ricardo Carneiro org., Atica, São Paulo. 